\title{
The hydrogeology of a moving cut slope and real time modelling of groundwater movement
}

\author{
I. Gray Sigra Pty Ltd, Australia \\ J. Wood Sigra Pty Ltd, Australia \\ B. Neels Sigra Pty Ltd, Australia
}

A. O'Brien Sigra Pty Ltd, Australia

\begin{abstract}
This paper covers the work undertaken to determine the behaviour of groundwater in a moving cut slope comprising fractured igneous rock overlying sedimentary deposits. The work was undertaken to provide part of a solution to the stabilisation of the slope through drainage. The work initially involved the installation of multiple piezometers and several pumping tests to determine the hydraulic conductivity and storage characteristics of the rock mass. Using this information a numerical model of the slope was created in which the time variant input was the piezometric head. Using the values of hydraulic conductivity and storage along with the varying piezometric information it was possible to determine where water was entering and leaving the slope during different weather events and to therefore optimise drainage design. The paper also describes the data acquisition and telemetry system developed and employed on this project and also some of the mathematics of drainage design. The paper also considers some drainage solutions to stabilise the slope more effectively than the cut and fill approach that has not yet succeeded.
\end{abstract}

\section{Introduction}

In 2008 the Department of Transport and Main Roads of Queensland had extended the Centenary Highway to the southwest of Brisbane. This work involved the creation of some cut slopes through hilly areas of quite complex geology. It was discovered shortly after the construction that there were some deep seated movements of two of the slopes towards the highway. This was initially detected by a need to re-grade the road surfaces which were distorting. Detailed surveys showed that the slopes were moving. One, referred to in this paper as cut 3, was moving essentially laterally at approximately $1 \mathrm{~mm}$ per day during dry periods with an acceleration to $3 \mathrm{~mm}$ per day during periods of significant rainfall. This level of movement was incompatible with road surfacing and a quite large investigation ensued with subsequent remedial works. Groundwater was implicated as being a significant contributor to the failure and a study ensued to see what effect it had. This paper describes the groundwater study and conclusions that were reached for cut 3 by the authors.

\section{Geology}

The cut 3 area is underlain by Triassic sandstone strata. These strata appear to be locally down-warped to the northwest in the southern flanks of the hillcrest to the south of cut 3 south. The Triassic sediments are typically composed of coarse grained sandstone strata that are locally intruded by trachyte dykes and sills. Coarse sandstones (identified in the southeastern flanks of the main ridge system) appear to be overlain by finer-grained, relatively weathered sandstone in the valley immediately to the east of cut 3 south. These sandstones appear to be down-warped to the north-northwest and locally eroded.

Tertiary sediments including claystones, mudstones, siltstones and minor clayey fine grained sandstones overlie the eroded Triassic contact. There are a series of tuffaceous components intercalated with the tertiary sediments giving rise to weak ductile horizons containing considerable smectite (sodium and calcium montmorillonites). 
A number of basalt flows are intercalated within the tertiary sediments. These basalts were extruded onto a claystone substratum, in some cases under shallow saline water conditions. Preferential alteration of the surrounding sediments, particularly in the contact areas is postulated. Thermal alteration of the underlying claystones is possible. This process may have given rise to localised hydrothermal activity and significant alteration within the basalt and surrounding sediment. Sodium enrichment of the montmorillonite with associated release of calcium into the sediments is likely, providing the mineral assemblage recognised in the extensive veining within the altered basalt and contact sediments. Several individual flow events are recognised with some events separated by claystone accumulation. Pillow structures, chemically altered matrix, vesicular and amygdaloidal zones and extensive areas of carbonate veining are recognised. These hydrothermal events have left weak, altered sediments which are likely to have very low angles of friction. This is consistent with back-analysis values that suggest that the angle of friction is about $8^{\circ}$ on the failure surface.

Trachyte was intruded into the sequence preferentially along strata within the claystone/ basalt sequence. Significant hydrothermal effects are noted within the trachyte contact zone. A contact breccia is recognised within the trachyte body and re-cemented breccia is typical of the lower contact zone. Significant areas of intense fracturing are recognised, particularly within the lower section of the trachyte body. The pattern of jointing is not systematically consistent with contraction due to cooling and a significant post injection phase of movement is postulated. Post injection fracturing may well be a function of settling of the trachyte mass into the ductile claystone material, particularly as the area progressively eroded to its current surface geometry.

In simplified terms what exists is a mass of highly jointed trachyte with an adjacent less jointed basalt sitting over a fine grained sedimentary rock with some alteration near the contact that has led to the development of clays with a very low friction angle. This low friction material formed the base of the failure.

\section{$3 \quad$ The landslide}

The landslide involved a movement of the trachyte and basalt over the sedimentary material below. In places sedimentary material was also entrained. The seat of this movement was at a depth several metres below the toe of the slope at road level under the cut slope. The exact nature of the failure near the road surface was never quite clear as it had compacted fill over it that had become distorted with movement of the material below it. Back from the roadway extensive monitoring by the Department defined the failure surface, or at least the upper part of it, fairly well. Many inclinometer holes were cut by movement on the failure surface. Some tension cracks could be viewed on surface at the back of the failure. The dimension of the moving area of cut 3 was approximately $120 \mathrm{~m}$ along the road and $100 \mathrm{~m}$ behind the road. The level difference between the back of the roadway and the back of the failing mass was at its maximum approximately $55 \mathrm{~m}$. At the western end of cut 3 is a gully, followed by an area called cut 4 which also shows movement.

Figure 1 is a plan of the area showing the roadway and the edge of the cutting. It also shows some of the very large number of boreholes that were drilled in the area. Figure 2 is an aerial photograph of the cut.

\section{$4 \quad$ Investigation of slope hydrogeology}

The change in rate of movement of the slope with rainfall indicated that pore pressures on the failure plane directly affected the stability of the slope. Understanding the hydrogeology was therefore very important. The questions needing answers were:

- What fluid pressures existed at the failure surface?

- What fluid supply and leakage maintained these pressures or led to their variation?

- Whether the fluid pressures could be reduced artificially and to what level? 
- What influence would a fluid pressure reduction have on slope stability?

- What system could be used to artificially lower the fluid pressures?

To be able to answer these questions we had to begin with a geological model and proceed to a hydrogeological model. Armed with this knowledge we could work out what we should be measuring and where. The geology was indeed complex in the overall sense however the subsurface shape of the igneous rock contact with the underlying sedimentary material was gradually becoming more defined by drilling and it appeared from the inclinometers that had been installed that the failure surface was close to this contact. The assumption made was that the fractured igneous rock was behaving as an unconfined aquifer overlying much less permeable material. This assumption proved to be correct but the question still remained as to the source of the water in it and where that water went to.

The depth of the failure surface from the upper portions of the slope was some $60 \mathrm{~m}$ with a groundwater head up to $25 \mathrm{~m}$ above it.

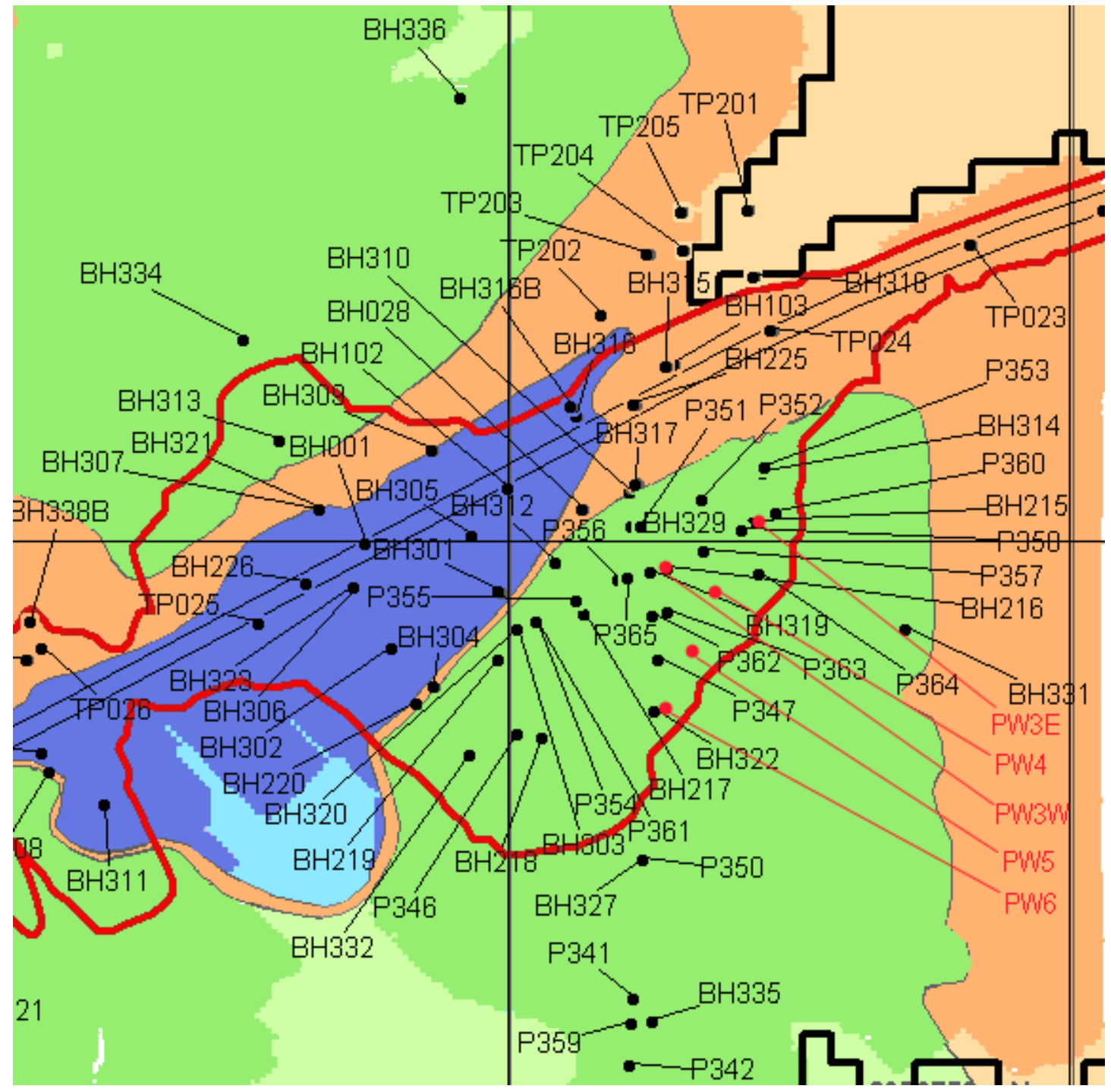

Figure 1 Plan of the area. The area of cut 3 in question is to the south of the roadway and is marked by the cut boundary (in red). The trachyte is shown in green, basalt in blue and sedimentary rocks in orange. Pumping test wells are shown in red. Most other holes contained piezometers 


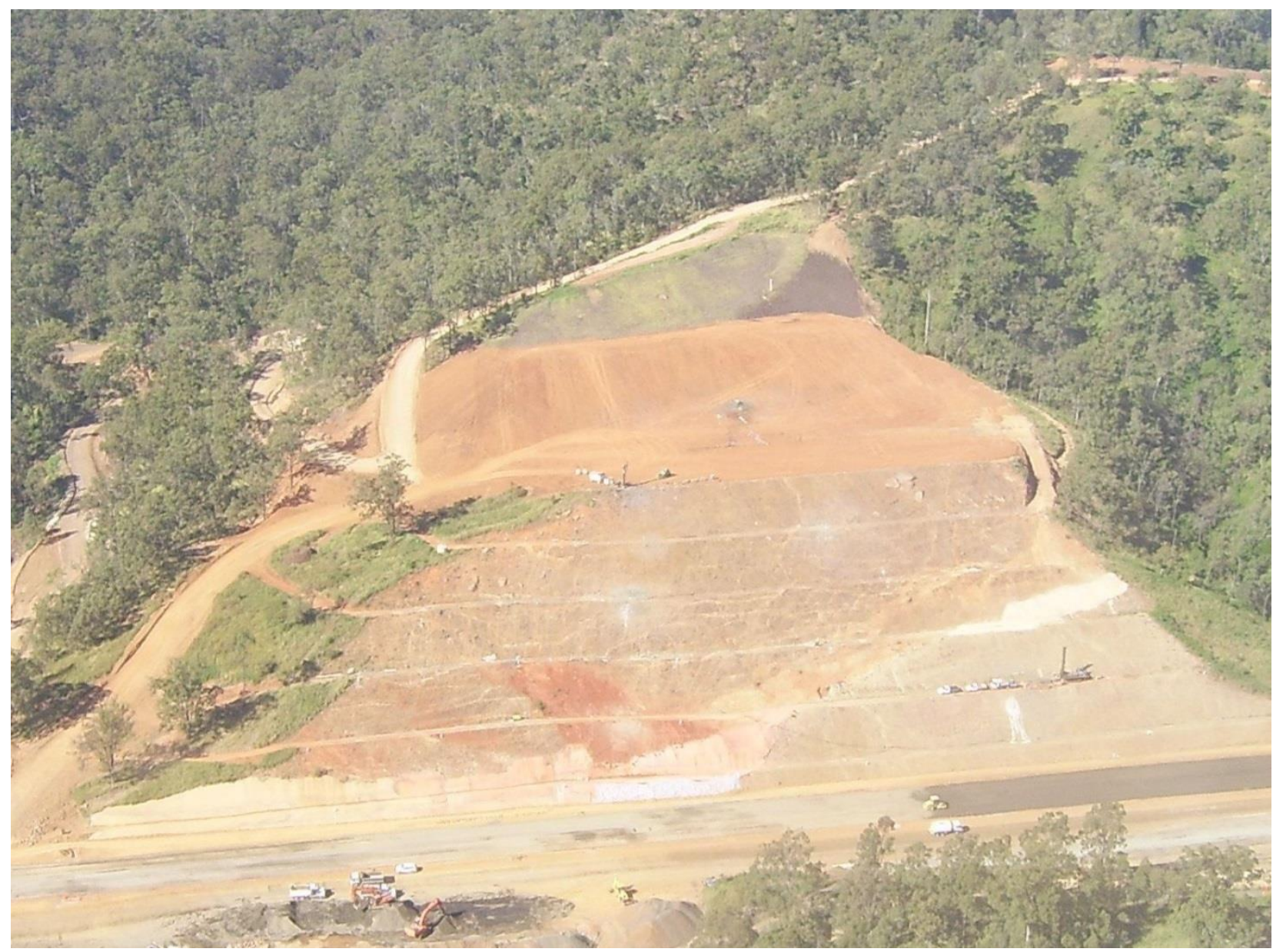

Figure 2 Aerial photograph of cut 3 during removal of the top of the slope and filling of the toe

The potential existed for the water to be coming from:

- The hill behind the slope.

- Springs below the failure surface.

- Infiltration during periods of rainfall.

The first process in determining this was in increasing the density of piezometers in the slope. This was not easy because the fractured trachyte collapsed into open holes shortly after drilling ceased. The only satisfactory way to drill was using a simultaneous casing advance system in which a standpipe could be installed through, and into which a pressure transducer could be installed. Care was taken to ensure no ingress of water could occur to the standpipe from surface or the upper zone of the hole.

Having placed an array of piezometers into the slope, five wells were created by essentially the same method, but were completed using perforated $114 \mathrm{~mm}$ outside diameter casing which was then fitted with a pressure transducer and an electric submersible pump. These wells are shown in Figure 1 along with other holes, most of which contained piezometers. The installation of any piezometers specifically to measure the fluid pressure in the material below the slip plane was difficult and their life short-lived due to the continuing movement. This meant that the determination of whether there was any water coming into the slope from below would have to be by indirect means.

\subsection{Well testing}

A series of well tests were undertaken to get the aquifer properties of the trachyte. Periods of rainfall leading to varying groundwater levels during the tests made some of their interpretations difficult but 
nevertheless some good and consistent results were achieved. The analysis methods used examined the drawdown under a constant discharge rate using Theis' method (Theis, 1935), Jacob's method (Jacob, 1950), recovery after a period of constant discharge using Theis' recovery method (Theis, 1935; Wenzel, 1942; reported by de Wiest, 1965) and in multi-rate testing using the method proposed by Sternberg (1968) and modified by Eden and Hazel (1973) as reported in Hazel (1975). Theis' recovery method gave the best result because of its comparative insensitivity to slight fluctuations in flow rate. It was followed by Jacob's method while the multi-rate testing gave indications of permeability. The results from the latter were complicated by rainfall during the test period and by changing near well bore loss terms. The well bore losses were in fact analysed in some detail using the approach of van Everdingen (1953) adapted from petroleum to water well units in Equation 1.

$$
\Delta h(\text { skin })=\frac{q \cdot S k}{2 \cdot \pi \cdot b \cdot K}
$$

Where:

$$
\begin{aligned}
\Delta h(\text { skin }) & =\text { the head loss at the well bore. } \\
q & =\text { the flow rate. } \\
S k & =\text { the skin term. } \\
K & =\text { the hydraulic conductivity. } \\
b & =\text { the aquifer thickness. }
\end{aligned}
$$

A skin term may be converted to an effective well bore radius through the relationship in Equation 2:

$$
r_{w}{ }^{\prime}=r_{w} \cdot e^{-S k}
$$

Where:

$$
\begin{aligned}
& r_{w}^{\prime}=\text { the effective well bore radius. } \\
& r_{w}=\text { the nominal well bore radius. } \\
& S k=\text { the skin term. }
\end{aligned}
$$

The results of the pumping tests are shown in Table 1.

Here it can be seen that the hydraulic conductivity was fairly consistent, as was the specific yield. The wells were found to be very well connected to the aquifer as the skin values varied between -0.6 and -0.7 which could also be thought of as the well bore having, in hydraulic terms, a diameter twice that drilled. Such a situation arises because the well was drilled with air and thus no mud was introduced to cause local losses and because the rock will have loosened around the screen as the casing was withdrawn.

Another aspect that was looked at was how the permeability values matched up with specific yield for a fractured rock mass. Equation 5 was used to derive a width of fractures for a given fracture spacing. Its derivation is presented from Equation 3. 
Table 1 The results of individual well testing in trachyte. The average specific yield value is calculated excluding the result of test 4 because of the proximity of the well and observation bore

\begin{tabular}{cccccc}
\hline Test \# & $\begin{array}{c}\text { Discharge } \\
\text { Bore }\end{array}$ & $\begin{array}{c}\text { Observation } \\
\text { Bore }\end{array}$ & $\begin{array}{c}\text { Hydraulic } \\
\text { Conductivity } \\
\text { m/day }\end{array}$ & $\begin{array}{c}\text { Calculated } \\
\text { Joint Width } \\
\boldsymbol{\mu m}\end{array}$ & Specific Yield \\
\hline 1 & PW5 & - & 0.388 & 87 & - \\
& & BH363 & 0.255 & 75 & 0.00175 \\
& PW4 & 0.342 & 83 & 0.00521 \\
2 & PW3W & 0.474 & 93 & 0.00182 \\
3 & PW4 & BH364 & 1.34 & 131 & 0.00124 \\
4 & PW3E & - & $0.52,0.71$ & $96 / 106$ & - \\
Geometric mean of hydraulic conductivity & 0.696 & 105 & 0.0141 \\
\multicolumn{2}{l}{ Mean of specific yield } & & & & $0.0025^{*}$ \\
\hline
\end{tabular}

The formula relating intrinsic permeability to hydraulic conductivity, Equation 3 is:

$$
k=\frac{K \mu}{g \rho}
$$

The relationship between intrinsic permeability and joint width and spacing which can be derived from fundamental laminar flow theory (Gray, 1983), is presented in Equation 4:

$$
k=\frac{a^{3}}{12} \cdot A
$$

By rearrangement:

$$
a^{3}=12 \cdot k / A
$$

Equation 5 can be used to yield a value for fracture width $a$

Where:

$$
\begin{aligned}
K & =\text { hydraulic conductivity }(\mathrm{m} / \mathrm{s}) . \\
k & =\text { intrinsic permeability }\left(\mathrm{m}^{2}\right) . \\
\mu & =\text { absolute viscosity }=0.0008 \mathrm{Nsm}^{-2} . \\
\rho & =\text { density }=992.2 \mathrm{~kg} / \mathrm{m}^{3} . \\
a & =\text { joint width }(\mathrm{m}) . \\
A & =\text { fracture density }=6.67 \mathrm{~m}^{-1 .} \\
g & =\text { gravity }=9.81 \mathrm{~ms}^{-2} .
\end{aligned}
$$

The values of the joint widths calculated on the basis of an observed average $150 \times 150 \mathrm{~mm}$ joint spacing are given in Table 1. The average value is 97 micron. It is useful to compare this with the joint width term derived from specific yield. Using the same fracture spacing the joint width may be calculated to be 187 micron. These two values are actually relatively similar as neither the effects of tortuosity on permeability (Kozeny, 1927; and Carman, 1937) nor the effects capillary pressure on specific yield are taken 
into account. This gives some level of confidence to the physical parameters. Surprisingly no delayed yield behaviour was observed (Boulton, 1954). This was probably due to a very low vertical permeability as opposed to none at all. It also was probably lost in the variable flow rates.

The tests showed no particular tendency for any clearly defined horizontally anisotropic permeability though the area was clearly not homogeneous.

While the well tests were used to derive the parameters of hydraulic conductivity and specific yield they were also run for some time often through rainfall events to see what drawdown they produced. A multi-well test produced a maximum drawdown of $14 \mathrm{~m}$ head. This level of drawdown could have a very significant effect on the slope's stability.

\subsection{The inflow and outflow from the slope}

To be able to design a drainage scheme to improve slope stability with any confidence it was essential to be able to know what water was coming and going from the slope. To achieve this, a numerical model of the eastern part of the cut 3 slope was created. This was a finite difference model of some $30 \times 40$ square blocks with a side dimension of $5 \mathrm{~m}$ and a thickness that was the difference between the phreatic surface and the base of the trachyte. This was quite unlike most finite difference groundwater models in that it was not designed to predict what might happen in the future or to be used to history match what had happened in the past. Its purpose was simply to work out what imbalances in block inflow existed from time step to time step.

The flow into each side of a block, Equation 6, was determined by the product of:

block side flow $=$ block width $\times$ potential gradient $\times$ geometric mean

(hydraulic conductivity $\times$ wetted thickness)

The potential gradient was calculated from the central point of adjacent blocks divided by the distance between them. The hydraulic conductivities and wetted thicknesses were also assessed at the block centres.

The difference in the sum of the side flows of each block constituted the net inflow or outflow rate from the block. Evaluating these inflow rates at the start and finish of a time step and multiplying this value by the time step provided an estimate of the net volume that should have been stored in the block in the time step under consideration. From this value was subtracted the amount of water stored in the block over the period under consideration. This was calculated as the change in wetted volume $\times$ specific yield for each block. The result was a net inflow or outflow from each block over the time step.

The absolute value of imbalance will be very dependent on the permeability but in essence the model is being used to look at the sum of the second derivative of slope in two dimensions with the subtraction of storage and pumping terms. The second derivative of slope is directly assessed from hydraulic head measurements in piezometers. There was really no basis for assigning differing hydraulic conductivity and specific yield results from each well test to a location and the decision was made to use the mean values shown in Table 1 in the model.

The model was run over a period extending from 24 November 2008 to 13 February 2009 during which time the piezometric levels, pumped volumes and rainfall were monitored with some precision. Figure 3 shows the various cumulative pump flows and rainfall with the time steps used in analysis being shown.

The piezometric levels for each block node at each time step were arrived at by using the measured piezometer information and using a Kriging interpolation algorithm. 


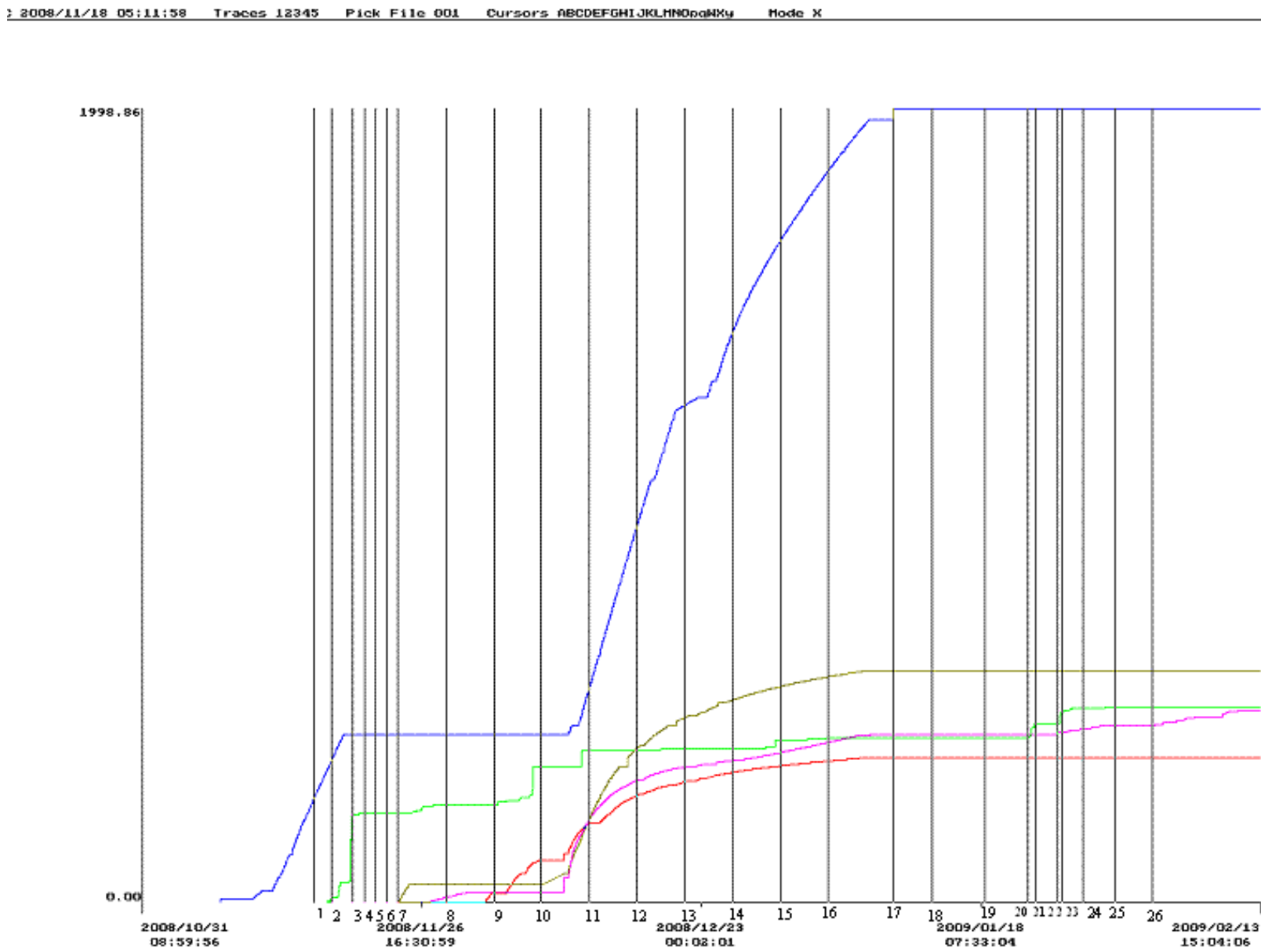

Figure 3 Cumulative plot of pumping on cut 3 with rainfall information. The numbers on the abscissa refer to specific time steps. Blue $=$ pump well 5 , green $=$ rainfall, brown $=$ pump well 4 , purple $=$ pump well ${ }_{3} \mathrm{E}$, Red $=$ pump well ${ }_{3} \mathrm{~W}$

While 26 time slices and 25 time steps were considered, an adequate view of the model may be obtained by looking at two time steps. These are presented graphically in Figures 4 and 5 . They are coloured contour plots which show calculated fluid imbalance on the basis of $\mathrm{mm}$ of equivalent inundation. The blue zones are areas where water is being supplied to maintain water levels. The green is where no water is being supplied while the yellow to red areas are where there is a net fluid loss. There are 61 colour graduations between -10 and $+10 \mathrm{~mm}$ equivalent rainfall. All plots are superimposed on a trachyte base RL.

Figure 4 shows the net calculated imbalance in the period from 1805 hrs on 18 November 2008 to $0500 \mathrm{hrs}$ on 20 November 2008. During this period $211 \mathrm{~mm}$ of rain fell and well 5 was being pumped. What can be seen is a moderate inflow over the upper and central portions of the slope with an exception of the area between PW5 and BH363 which shows a net loss. There are two singularities which indicate apparent fluid gain. One of these is between benches 2 and 3 in the vicinity of BH365 and pump well 3W. The other is between benches 3 and 4 in the vicinity of pump well $3 \mathrm{E}$ and BH364. Around and below bench 2 we seem to have a zone of significant fluid loss. This probably corresponds to existing horizontal drains taking fluid out of the trachyte bowl. 


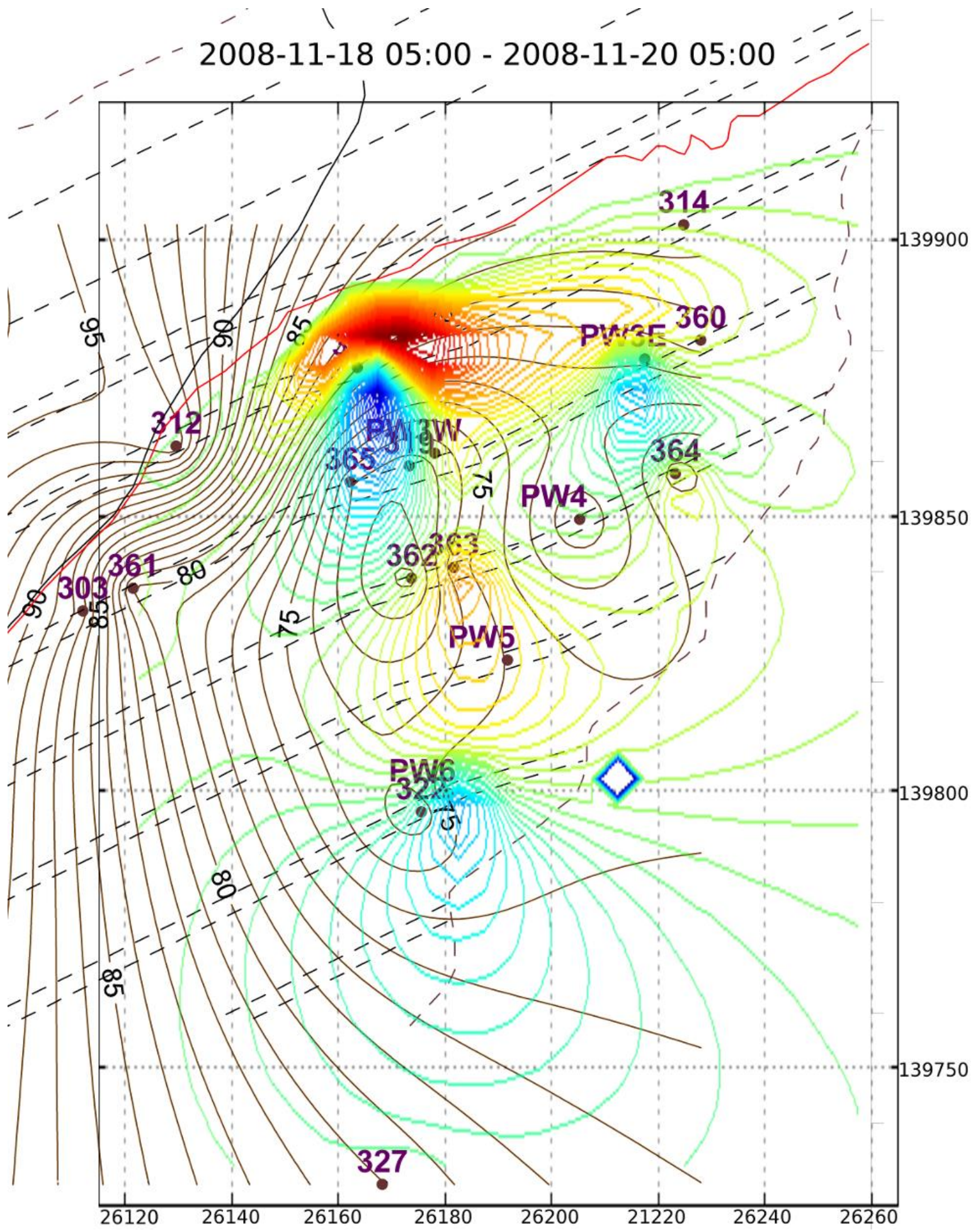

Figure 4 The net calculated imbalance $(\mathrm{mm})$ in the period from 1805 hrs on 18 November2008 to 0500 hrs on 20 November 2008 corresponding to time steps 2 to 3 on Figure 3. During this period $211 \mathrm{~mm}$ of rain fell and well 5 was being pumped 


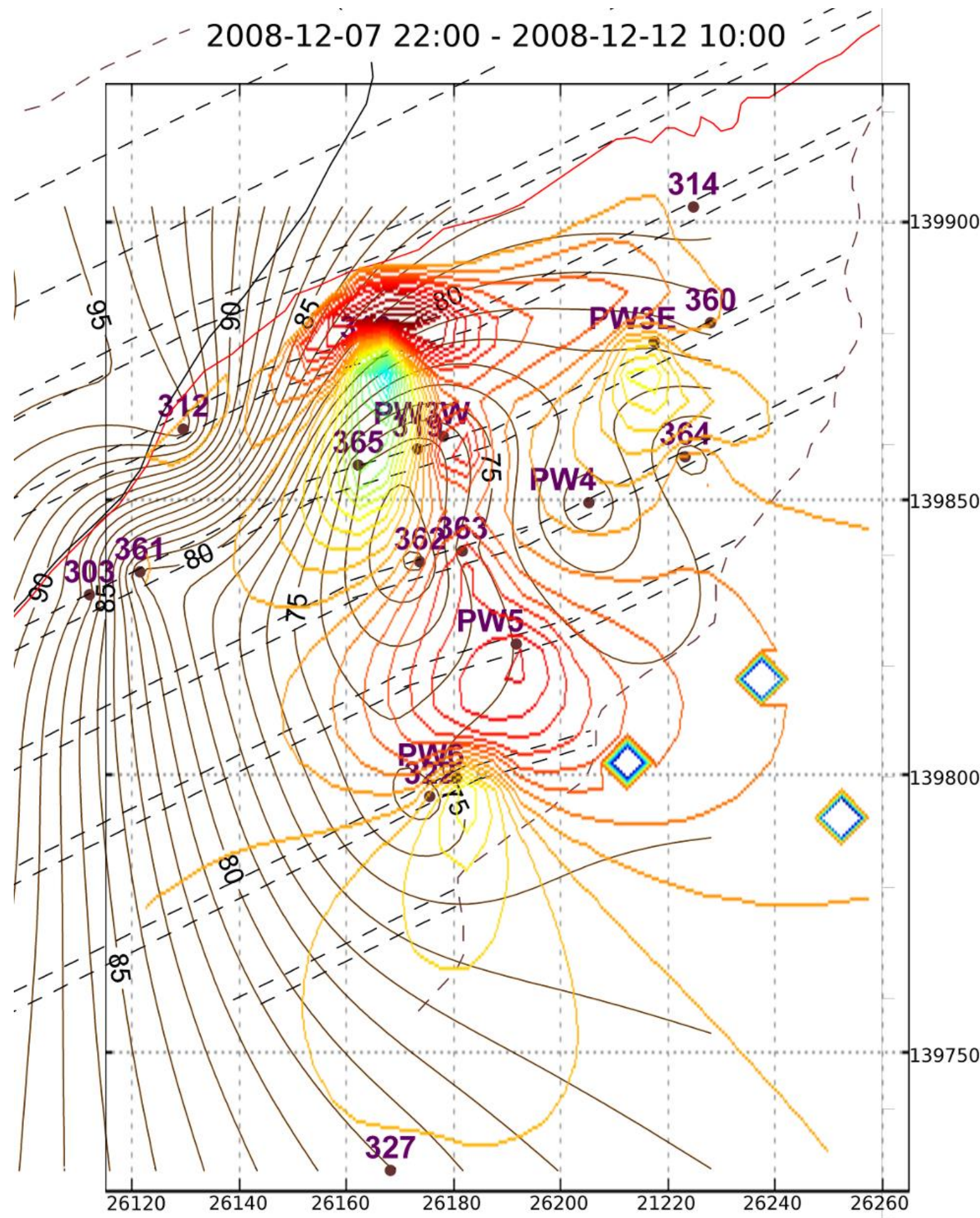

Figure 5 The net calculated imbalance $(\mathrm{mm})$ in the period from $2200 \mathrm{hrs}$ on 7 December 2008 to 1000 hrs on 12 December 2008 corresponding to time steps 8 to 9 on Figure 3. During this period $41 \mathrm{~mm}$ of rain fell and pumping tests were conducted on the four wells $3 \mathrm{E}$, $3 \mathrm{~W}, 4$ and 5

Figure 5 shows the net calculated imbalance for the period from 2200 hrs on 7 December 2008 and $1000 \mathrm{hrs}$ on 12 December 2008. During this period $41 \mathrm{~mm}$ of rain fell and pumping tests were conducted on the four wells $3 E, 3 W, 4$ and 5 . The overall picture with the exception of the singularity around pump well $3 \mathrm{~W}$ and $\mathrm{BH} 365$ is one of fluid loss. This fluid loss is independent of the pumping which has been taken into 
account in the solution. As would be expected this means that the slope is drying out in periods of reduced rain.

The net inflow rates calculated for the slope over the time steps are shown in Table 2.

Table 2 Apparent mean slope infiltration and rainfall

\begin{tabular}{|c|c|c|c|c|c|c|c|c|}
\hline Start Date & Hrs & End Date & Hrs & $\begin{array}{l}\text { Net } \\
\text { Inflow } \\
\text { mm }\end{array}$ & $\begin{array}{l}\text { Net Inflow } \\
\text { Rate } \\
\text { mm/day }\end{array}$ & $\begin{array}{l}\text { Net } \\
\text { Rain } \\
\text { mm }\end{array}$ & $\begin{array}{c}\text { Rain } \\
\text { Intensity } \\
\text { mm/day }\end{array}$ & $\begin{array}{c}\text { Rainfall } \\
\text { Description }\end{array}$ \\
\hline 16 Nov. 2008 & 14 & 18 Nov. 2008 & 05 & 0.93 & 0.57 & 8.00 & 4.92 & Light \\
\hline 18 Nov. 2009 & 05 & 20 Nov. 2008 & 05 & 1.21 & 0.60 & 211.00 & 105.50 & $\begin{array}{l}\text { Heavy }(19 / 11) \\
\text { Deluge }(20 / 11)\end{array}$ \\
\hline 20 Nov. 2008 & 05 & 21 Nov. 2008 & 06 & 2.98 & 2.86 & 5.60 & 5.37 & \\
\hline 21 Nov. 2008 & 06 & 22 Nov. 2008 & 07 & 2.73 & 2.62 & 0.60 & 0.57 & \\
\hline 22 Nov. 2008 & 07 & 23 Nov. 2008 & 09 & 2.55 & 2.35 & 0.00 & 0.00 & \\
\hline 23 Nov. 2008 & 09 & 24 Nov. 2008 & 11 & 2.51 & 2.31 & 0.00 & 0.00 & \\
\hline 24 Nov. 2008 & 11 & 28 Nov. 2008 & 22 & 0.59 & 0.13 & 18.00 & 4.03 & Steady \\
\hline 28 Nov. 2008 & 22 & 3 Dec. 2008 & 10 & 0.56 & 0.12 & 0.00 & 0.00 & \\
\hline 3 Dec. 2008 & 10 & 7 Dec. 2008 & 22 & 0.57 & 0.12 & 98.20 & 21.81 & $\begin{array}{c}\text { Steady, heavy } \\
(7 / 12)\end{array}$ \\
\hline 7 Dec. 2008 & 22 & 12 Dec. 2008 & 10 & 0.61 & 0.13 & 41.40 & 9.20 & Heavy $(12 / 12)$ \\
\hline 12 Dec. 2008 & 10 & 16 Dec. 2008 & 22 & 0.62 & 0.13 & 0.00 & 0.00 & \\
\hline 16 Dec. 2008 & 22 & 21 Dec. 2008 & 10 & 0.52 & 0.11 & 4.00 & 0.88 & \\
\hline 21 Dec. 2008 & 10 & 25 Dec. 2008 & 22 & 0.50 & 0.11 & 0.00 & 0.00 & \\
\hline 25 Dec. 2008 & 22 & 30 Dec. 2008 & 10 & 0.37 & 0.08 & 22.40 & 4.97 & Steady $(25 / 12)$ \\
\hline 30 Dec. 2008 & 10 & 3 Jan. 2009 & 22 & 0.37 & 0.08 & 3.60 & 0.80 & Light \\
\hline 3 Jan. 2009 & 22 & 8 Jan. 2009 & 16 & 0.33 & 0.07 & 0.00 & 0.00 & \\
\hline 8 Jan. 2009 & 16 & 13 Jan. 2009 & 16 & 0.29 & 0.05 & 0.00 & 0.00 & \\
\hline 13 Jan. 2009 & 16 & 18 Jan. 2009 & 16 & 0.27 & 0.05 & 0.00 & 0.00 & \\
\hline 18 Jan. 2009 & 16 & 22 Jan. 2009 & 15 & 0.34 & 0.08 & 0.00 & 0.00 & \\
\hline 22 Jan. 2009 & 15 & 23 Jan. 2009 & 09 & 1.85 & 2.46 & 37.60 & 50.13 & Heavy $(23 / 1)$ \\
\hline 23 Jan. 2009 & 09 & 25 Jan. 2009 & 10 & 0.76 & 0.37 & 0.00 & 0.00 & \\
\hline 25 Jan. 2009 & 10 & 25 Jan. 2009 & 21 & 3.32 & 7.24 & 30.40 & 66.32 & Heavy (25/1) \\
\hline 25 Jan. 2009 & 21 & 27 Jan. 2009 & 21 & 0.76 & 0.38 & 8.40 & 4.20 & \\
\hline 27 Jan. 2009 & 21 & 30 Jan. 2009 & 21 & 0.54 & 0.18 & 0.80 & 0.26 & \\
\hline
\end{tabular}

\subsection{Conclusions on hydrogeology}

Despite the complex geology of the landslide the hydrogeology of the trachyte to the eastern side of cut 3 seems to be relatively simple. The general behaviour is of fairly uniformly fractured rock, a low specific yield $(0.0025)$ and a high horizontal hydraulic conductivity $(0.52 \mathrm{~m} /$ day). Water flows in the trachyte are from the 
south east driven by hydraulic gradient and turn to the north. Around bench 2 there is a steep hydraulic gradient as the trachyte base rises with mudstone below. In general terms the inflow to the slope seems to be derived from rainfall. The mean normal infiltration rate under steady rain appears to be about $3.0 \mathrm{~mm} /$ day with a peak of $7.2 \mathrm{~mm} /$ day. These figures correspond to potential head rises of 1.2 and $2.9 \mathrm{~m} /$ day for the measured specific yield. These low values of apparent vertical flow are very different from the near horizontal permeabilities. If the fractured model is correct and we can measure $0.52 \mathrm{~m} /$ day horizontal hydraulic conductivity in one direction then with two sets of vertical joints one could reasonably expect twice this value to act vertically. This would lead to potential infiltration rates of $1,000 \mathrm{~mm} /$ day. The low infiltration is consistent with the nick points where streams start at quite high levels on the slope and carry water from it.

However the water inflow pattern is not quite as simple as direct vertical infiltration. The measured head rises with rainfall varied in the 7 December 2008 storm between $0.2 \mathrm{~m}$ on the west of the trachyte where it abuts the basalt on bench to 3 to $4 \mathrm{~m}$ at the east of bench 3 . The times for the water levels to peak also vary with $14 \mathrm{hrs}$ to the west and $30+\mathrm{hrs}$ to the east. This storm deposited $73 \mathrm{~mm}$ of rain in $33 / 4 \mathrm{hrs}$. These are indicators that the hydrogeological behaviour of the slope is not homogeneous.

What is hypothesised to be the case is that the vertical joints are open but are not continuous across horizontal joints. The reason for this is that there has been some movement in the plane of the horizontal joints and that silts or clays have deposited at the base of the vertical fractures greatly reducing the conductivity between vertical fracture sets.

This behaviour is consistent with what has been observed when rainfall occurs. There is surface runoff but in addition there are obvious weeping joints and levels. This is particularly the case adjacent to the contact with the basalt. The effects of two phase flow and the presence of air cushions in the joints which prevent vertical flow should not be discounted either.

The groundwater imbalance model also shows some variability. There is a reasonably consistent apparent source between bench 2 and 3 in the vicinity of BH317. This corresponds to a slow time to peak following a storm. There is also an apparent source in the vicinity of pump well $3 \mathrm{E}$ which corresponds to a major storm rises and maximum time to peak. The third apparent source area is near pump-well 6 . There appears to be a consistent major sink zone between benches 1 and 2. It is thought that sink is due to the presence of horizontal drains but it may also be associated with a natural feature.

With the exception of these four features the slope seems to behave fairly uniformly gaining water with rain and losing it in dry periods. The fact that the slope does appear to maintain a net inflow from the sedimentary rocks below is a good indicator that artesian conditions do not exist below the trachyte.

The area to the west of the cut 3 which is substantially covered with basalt was largely missed by this study.

\section{$5 \quad$ Data acquisition systems used in the operation}

The piezometric levels were and still continue to be gathered from vibrating wire and quartz bridge transducers in the wells using Sigra data loggers. These are also used to control the pump wells. Data is gathered from loggers on the cut slope and transmitted back across the roadway to a base logger using the licence free $433.92 \mathrm{MHz}$ spectrum radios. Sometimes this transmission is direct while at other times it is via another logger used on the slope in a daisy chain mode. This is necessary as some of the loggers were out of line of sight of the base unit or are a long way from it (those on the adjacent cut).

The base logger is connected to a NextG (Telstra Service) data modem connected to a private Wide Area Network (WAN) for the collection of logger data. This service provides a network that is not accessible from the internet. The Sigra server is used to download this data daily via a secure virtual private network (VPN) connection. More frequent downloads can be achieved if required for alarm monitoring. Alarm conditions are checked by the Sigra server at every download. If a threshold condition (value or rate of change) is exceeded then an email and SMS message is sent automatically. 
The individual loggers also have incorporated within their software the capability to make a decision on whether a threshold is exceeded and to communicate via a modem an SMS warning.

The loggers have the ability to record only on value change or rate and this reduces the amount of information that must be stored and transmitted.

The data on the server may be made available online via a secure graphical interface. It may also be used directly by software used to analyse what is happening on the slope. This can be a real time model of piezometric level and net inflows and outflows from the slope.

\section{Use of the hydrogeological information in designing slope drainage}

Good hydrogeological information is vital to a proper drainage design to improve slope stability. This study has revealed not only the values of hydraulic conductivity and specific yield but, through the modelling process, where water enters and leaves the slope. One of the most important items of information derived from it is the net infiltration rate. This gives a basis for designing a drainage pattern that will drain the area.

This can be done on the basis of a design to cope with steady state infiltration at a maximum rate while maintaining a groundwater level below a limit. Alternatively it may be a design which permits the piezometric level to rise within limits and then drains it adequately and quickly. The latter would permit greater drain or well spacing, but would come with a greater risk.

\subsection{Useful design equations for dewatering wells}

The authors have experience in both oilfield reservoir theory and design and have taken some of these principles to produce two equations which are useful for dewatering design. The first is taken directly from bounded reservoir theory and is converted to water well terms. The second has been developed from a similar background. The concept of a bounded reservoir does not require a sealing physical boundary around a well but is usually created by the presence of adjacent wells which are also operating in a grid pattern drawing water towards them. The use of these equations is in designing appropriate well spacings for drainage.

\subsubsection{Semi steady state radial flow}

In a bounded reservoir with a central well there will be an initial period of transient flow surrounding a pumped well following which a situation of stable decline called semi-steady state flow will be established. Dake (1978) describes these well in oilfield terms. In water well terms we may say that in a circular or hexagonal bounded zone the transient behaviour persists until the dimensionless time $t_{D A}$ for the area exceeds 0.1, Equation 7.

$$
t_{D A}=\frac{K \cdot b \cdot t}{A \cdot S}
$$

Where:

$$
\begin{aligned}
& t_{D A}=\text { the dimensionless time. } \\
& K \quad=\text { the hydraulic conductivity. } \\
& b \quad=\text { the reservoir (aquifer) thickness. } \\
& t \quad=\text { the time. } \\
& A \quad=\text { the bounded reservoir's area. } \\
& S \quad=\text { the specific yield or storativity. }
\end{aligned}
$$


Following this the bounded area's flow will decline according to the semi steady state flow relation presented in Equation 8:

$$
q=\frac{2 \cdot \pi \cdot b \cdot K\left(h_{a v e}-h_{f}\right)}{\ln \left(\frac{r_{e}}{r_{w}}-\frac{3}{4}+S k\right)}
$$

Where:

$$
\begin{aligned}
& q=\text { the flow rate. } \\
& b \quad=\text { the reservoir (aquifer thickness). } \\
& K=\text { the hydraulic conductivity. } \\
& h_{a v e}=\text { the average reservoir head. } \\
& h_{f}=\text { the head in the flowing well bore. } \\
& r_{e}=\text { the radius of the bounded reservoir. } \\
& r_{w}=\text { the radius of the well. } \\
& S_{k}=\text { the skin term. }
\end{aligned}
$$

It should be born in mind that a producing cell of a reservoir may be bounded by the presence of other wells as much as by a physical boundary.

\subsubsection{Steady state radial inflow with infiltration}

If we have a bounded circular aquifer with a constant rate of infiltration per unit area then the central well must produce all that infiltration to maintain steady state. Equation 9 describes the well bore head in terms of the outer boundary head for an aquifer with a free upper surface. The outer boundary head is very close to the mean aquifer head.

$$
h_{w}=\sqrt{\left(h_{e}^{2}-\frac{n}{K} \cdot\left(r_{e}^{2} \cdot \ln \frac{r_{e}}{r_{w}}-\frac{r_{e}^{2}}{2}+\frac{r_{w}^{2}}{2}\right)\right)}
$$

Where:

$$
\begin{aligned}
& h_{w} \quad=\text { the head at the effective well bore. } \\
& h_{e}=\text { the head at the outer radius. } \\
& K \quad=\text { the hydraulic conductivity. } \\
& n \quad=\text { the infiltration per unit area per unit time. } \\
& r_{w}=\text { the well bore radius. } \\
& r_{e} \quad=\text { the outer radius. }
\end{aligned}
$$

This equation forms the basis for design of well spacing under conditions of continuous infiltration.

\section{$7 \quad$ Conclusions}

This paper presents the work that was undertaken to determine what eventuated as being a fairly straightforward groundwater regime on a cut slope through complex geology. The process was one of determining the basic groundwater parameters through the use of piezometers and pumping tests. This was followed by a period of monitoring via a sophisticated data acquisition system through various rainfall events and pumping regimes. A finite difference groundwater model was created that analysed this data in 
terms of the net inflow or outflow from different parts of the slope. This showed quite conclusively that the principal inflow was from rainfall but at a much lower rate than might have been expected. The reason for this low rate is considered to be limited vertical permeability. This lowered permeability may however only exist near the surface as no delayed yield effects were observed during pumping tests.

Such a model as this has the potential to be run in real time to permit analysis of slope events and help understand the development of untoward inflows. It could also be coupled to a stability model which could also run in real time and provide a warning of imminent problems.

The paper presents some useful equations derived from oilfield reservoir engineering that may be used to design a well pattern used to drain such a slope.

From the test work that was conducted several drainage options were considered to improve stability. The use of simple sub horizontal drains that would drain under gravity was not an option as the bulk of the failure surface was well below the ground surface. Directional wells drilled principally in the sedimentary material below the failure surface and designed to pop up into the trachyte were thought about but not considered suitable. The reason for this is that the failure surface was in the sedimentary material which would cut through and seal off the boreholes so that they could not effectively drain the trachyte.

A simple vertical well drainage pattern could have certainly lowered the water table very substantially but would have required an additional 52 wells to be drilled, powered and maintained over the slope. The reason for this number of wells was to ensure that ground water inflow during storms would not rise above the base of the trachyte by more than two metres. The overall well spacing in this case would be $20 \mathrm{~m}$ which would allow for some wells to fail without catastrophic consequences. These wells were designed with an enlarged (by jetting) coarse sand filled base through the failure zone to ensure drainage right into this area. This option was considered by the client to be excessively complex to maintain though of low cost to install (AUD 3.1 M in 2009).

A preferred drainage design for the slope was arrived at using boreholes that were drilled angled downwards from the road to intersect pumped caissons in the slope. This approach would have enabled the drainage to be accomplished using straight boreholes rather than directionally drilled holes. The use of straight holes would have permitted the use of a simultaneous casing advance drilling method which was shown to be suitable to drill through the hard fractured trachyte. The use of gathering caissons in which pumps could be installed simplified the maintenance of the pumping system on the slope compared to the multiple vertical well option. The cost of installing such a system was considered to be AUD $6 \mathrm{M}$ in 2009. A plan view of this option is shown in Figure 6 .

This approach should have stabilised the slope in its own right as it offered greater improvements in Factor of Safety than the approach which was actually taken. The latter was a more conservative approach which involved cutting the top off the slope and building up the roadway over the toe of the slope while maintaining the test wells as the slope's sole means of drainage. The actual cost of these works was about AUD $30 \mathrm{M}$. However, the slope is still continuing to move slowly and at a slightly greater rate following periods of heavy rain. It continues to be monitored to ensure that it does not create a hazard.

\section{Acknowledgement}

The authors wish to thank the Queensland Department of Transport and Main Roads for permission to publish the site specific information contained in this paper. It should however be noted that the opinions contained in this paper are those of the authors. 


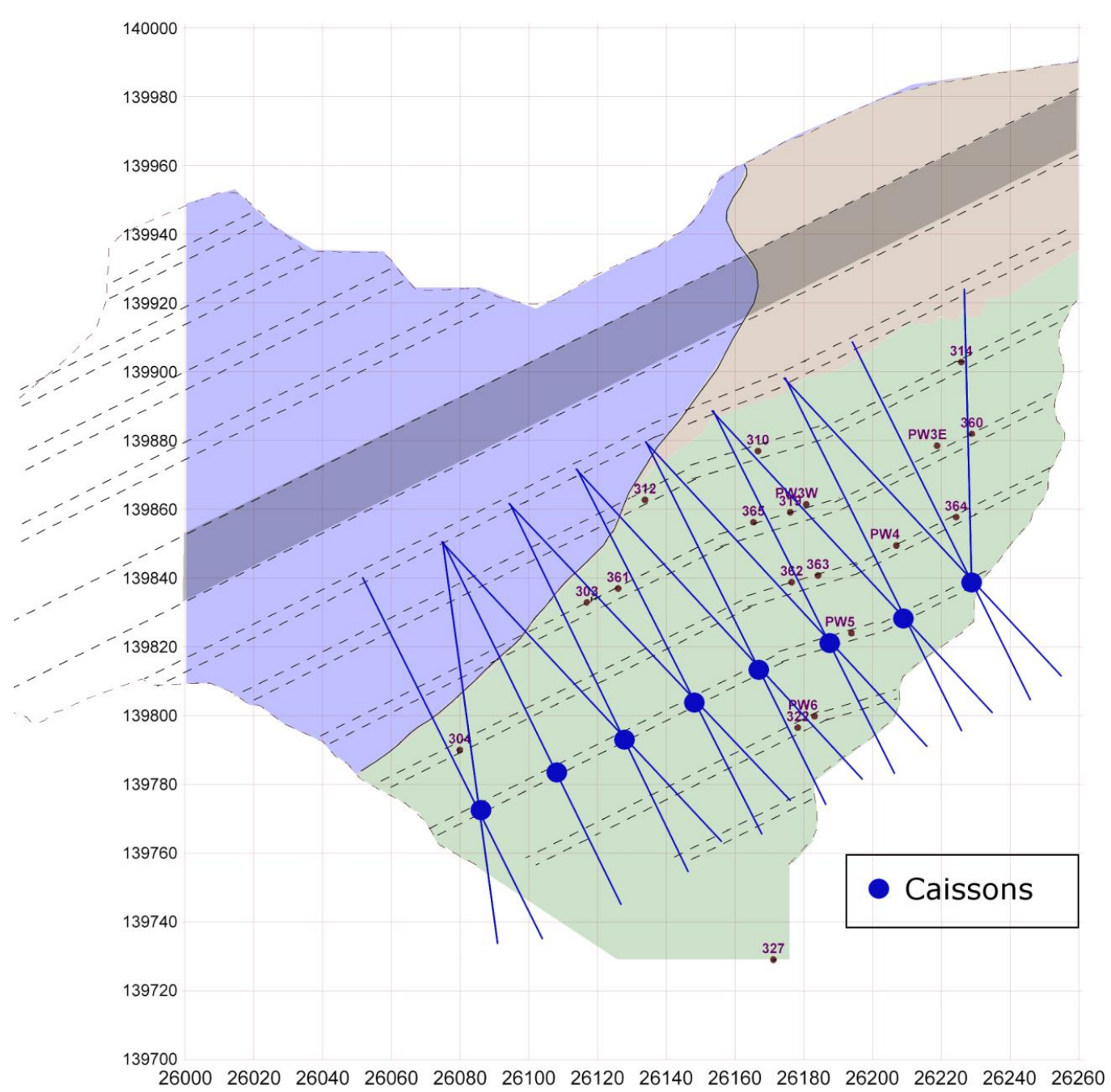

Figure 6 The favoured design using drilled dipping drains that pass through pumped caissons

\section{References}

Boulton, N.S. (1954) Unsteady residual flow to a pumped well allowing for delayed yield from storage, International Association of Hydrology, pub. 37.

Carman, P.C. (1937) Fluid flow through granular beds, Transactions of the Institution of Chemical Engineers, Institution of Chemical Engineers, London, Vol. 15, pp. 150-166.

Dake, L.P. (1978) Fundamentals of Reservoir Engineering, Developments in Petroleum Science, Elsevier, Vol. 8.

de Wiest, R.M. (1965) Geohydrology, John Wiley \& Sons, Inc., New York.

Eden, R.N. and Hazel, C.P. (1973) Computer and graphical analysis of variable discharge pumping tests of wells, Civil Engineering Transactions, The Institution of Engineers Australia, pp. 5-10.

Gray, I. (1983) Factors influencing out bursting and gas drainage in underground coal mines, PhD Thesis, The University of New South Wales, Kensington.

Hazel, C.P. (1975) Groundwater Hydraulics, The Irrigation and Water Supply Commission, Queensland, Lectures.

Jacob, C.E. (1950) Flow of groundwater, in Engineering Hydraulics, H. Rouse (editor), John Wiley \& Sons, Inc., New York, p. 346.

Kozeny, J. (1927) Ueber kapillare Leitung des Wassers im Boden, Akademie der Wissenschaft, Wien (about capillary transport of water in soil. Proceedings of Science Academy, Vienna), 136(2a), pp. 271-306.

Sternberg, Y.M. (1968) Simplified solution for variable rate pumping test, Journal of the Hydraulics Division, American Society of Chemical Engineers, Vol. 94(HY1), pp. 177-180.

Theis, C.V. (1935) The relation between the lowering of the piezometric surface and the rate and duration of discharge of a well using groundwater storage, American Geophysical Union Transactions, American Geophysical Union, Vol. 16, pp. 510-524.

van Everdingen, A.F. (1953) The skin effect and its impediment to fluid flow into a wellbore, Transactions AIME, American Institute of Mining, Metallurgical, and Petroleum Engineers, Vol. 198, pp. 171-176.

Wenzel, L.K. (1942) Methods for determining permeability of water-bearing materials with special reference to discharging-well methods, U.S. Geological Survey, Washington, D.C., Water-Supply Paper 887, 192 p. 